\title{
A ABORDAGEM ERGONÔMICA NO ESTUDO DAS POSTURAS DO TRABALHO: O CASO DE UMA FÁBRICA DE JÓIAS
}

\author{
THE ERGONOMICS APPROACH IN THE STUDY \\ OF THE POSTURES OF THE WORK: THE \\ CASE A JEWEL INDUSTRY
}

\author{
Gisele Beatriz de Oliveira Alves ${ }^{(1)}$, Ada Ávila Assunção ${ }^{(2)}$, \\ Micheline Gomes da Luz $^{(3)}$
}

\begin{abstract}
ALVES, G.B.O., ASSUNÇÃO, A.A., LUZ, M.G. Posturas do trabalho: o caso de uma fábrica de joias. Rev. Ter. Ocup. Univ. São Paulo, v. 13, n. 3, p. 111-7, set./dez. 2002.

RESUMO: O objetivo do artigo é discutir a prática da Terapia Ocupacional na avaliação das posturas adotadas pelos trabalhadores em situação real. Realizou-se um estudo ergonômico em uma fábrica de jóias, onde foram realizadas entrevistas abertas com os trabalhadores e gerentes, análises das posturas adotadas, descrição da duração dos ciclos de trabalho, e avaliação dos critérios informais e formais de qualidade na produção das peças. Os resultados colocam em evidência o caráter repetitivo do trabalho nos postos estudados, mas, cujos componentes são heterogêneos exigindo atenção e concentração. Essas funções cognitivas e outros determinantes influenciam as posturas adotadas. Discute-se ao final, o mito da postura ideal e os limites de uma prática da Terapia Ocupacional que não integre a análise do sentido das posturas adotadas em suas avaliações.
\end{abstract}

DESCRITORES: Estudos de avaliação. Terapia ocupacional/tendências. Postura. Engenharia humana. Entrevistas. Indústrias/classificação. Trabalhadores.

\section{INTRODUÇÃO}

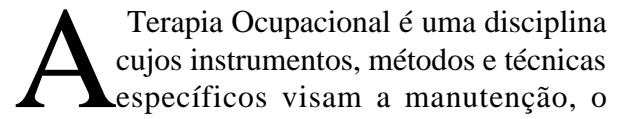

aumento e a recuperação do desempenho funcional dos indivíduos. Nos últimos anos, cresceu como especialidade no mundo todo, e, recentemente, tem sido

\footnotetext{
(1) Professora do Departamento de Terapia Ocupacional da Universidade Federal de Minas Gerais. Terapeuta Ocupacional. Mestre em Ergonomia.

(2) Professora do Departamento de Medicina Preventiva e Social da Universidade Federal de Minas Gerais. Médica do Trabalho. Mestre e Doutora em Ergonomia.

(3) Terapeuta Ocupacional. Estagiária do Laboratório de Ergonomia / DEP / Universidade Federal de Minas Gerais.

Endereço para correspondência: Gisele Beatriz Alves. Departamento de Terapia Ocupacional. Escola de Educação Física, Fisioterapia e Terapia Ocupacional. Universidade Federal de Minas Gerais. Unidade Administrativa II - $3^{\circ}$ andar, Campus Universitário/ Pampulha. Avenida Antônio Carlos, 6627. CEP: 31270-901. Belo Horizonte, Minas Gerais.
} 
convocada a intervir diretamente nos ambientes de trabalho. Contribuiu para essa expansão a incidência aumentada de problemas músculo-esqueléticos associados ao trabalho. Ou seja, o tripé (1) atividades de vida diária, (2) lazer, e (3) trabalho (AJOT, 1999), sobre o qual se assenta as ações da Terapia Ocupacional, tendo como objetivo habilitar os indivíduos para que possam se engajar naqueles papéis, tarefas e atividades que têm significado em seu cotidiano (TROMBLY, 1993), mostrou sua relevância social no mundo do trabalho, colocando novas exigências teóricometodológicas para a referida disciplina.

Este artigo visa fornecer elementos, a partir da descrição dos resultados de um estudo realizado em uma indústria de jóias, para o debate sobre a pertinência da análise ergonômica do trabalho na prática do terapeuta ocupacional.

Como será apresentado, a análise das posturas assumidas pelos trabalhadores da empresa estudada coloca em evidência os componentes estáticos e dinâmicos das mesmas, os quais, segundo a literatura, têm sido associados à vários problemas músculoesqueléticos e constituem-se em agentes provocativos de dor, desconforto, limitação de movimentos e prejuízos funcionais.

Alguns estudos em Terapia Ocupacional que abordam as posturas laborais enfatizam a importância da reeducação postural sem explicitar os critérios para modificar as condições físicas e materiais de trabalho, por exemplo: dimensões do mobiliário, ferramentas, dispositivos dos equipamentos, iluminação, vibração etc. Isto é, não são orientados para compreender os determinantes das mesmas em situações reais de trabalho. Os estudos avaliam as posturas caracterizandoas como "corretas" ou "incorretas", sem considerar as ações dos trabalhadores. Esses estudos se norteiam pela idéia de que a postura é o resultado de decisões e hábitos pessoais, sendo assim, acredita-se que a "educação postural" seria o suficiente. Ou seja, na sua abordagem teórico-prática a Terapia Ocupacional não incorpora a concepção (defendida pela ergonomia francesa), de que a postura ideal é um mito, pois, como afirma Lima (2000a): "a postura assumida por um trabalhador nunca é somente o resultado de idiossincrasias pessoais, mas é determinada pela interrelação complexa dos múltiplos fatores constituintes da situação de trabalho".

\section{MÉTODOS}

Através de análise dos resultados de um estudo ergonômico realizado numa fábrica de jóias, procuramos elucidar porquê os indivíduos adotam as posturas estereotipadas observadas, e a seguir serão apresentados os argumentos que colocam os limites da prática do terapeuta ocupacional.

Ergonomia é a disciplina que estuda o trabalho, os seus objetivos são: entender o trabalho, evitar problemas de saúde e melhorar a eficiência da produção (ABRAHÃO, 2000).

A preocupação central da ergonomia é colocar em evidência a relação entre as coisas, por exemplo, entre os objetivos do trabalho, os meios disponíveis, e a saúde da população. Através da análise ergonômica é possível aproximar-se das dificuldades enfrentadas no cotidiano do trabalho, as quais podem se originar do conflito entre a racionalidade do sistema e a racionalidade operatória. $\mathrm{O}$ ergonomista analisa as tarefas no contexto onde elas são realizadas. Os mecanismos através dos quais o ser humano atinge os objetivos desejados estão no centro desta análise que pretende ao final fornecer elementos para a transformação das situações. A análise ergonômica do trabalho (AET) tem como objetivo, sobretudo, compreender como o trabalhador faz para "fazer" a sua tarefa (LIMA, 2000b). Na perspectiva da ergonomia, para entender o que é o trabalho de uma pessoa, é necessário observar e analisar o desenrolar de sua atividade em situações reais, em seu contexto, procurando identificar tudo o que muda e faz o trabalhador tomar micro-decisões a fim de resolver os pequenos mas recorrentes problemas do cotidiano da produção (ASSUNÇÃO; LIMA, 2002).

A ergonomia não considera o trabalhador como um mero executante de tarefas. Ele age à medida em que é confrontado com uma determinada situação, interpreta os dados disponíveis e mensura o tempo alocado para cada operação, ou seja, ele regula - e é assim que obtém os resultados desejados. Sem essa capacidade de se moldar aos objetivos da produção que ele incorpora, não há trabalho, não há produto final (ASSUNÇÃO, 2001).

Os princípios apresentados acima orientam a abordagem do campo. Realizou-se um estudo ergonômico entre junho e dezembro de 2000, solicitado pelo departamento de recursos humanos da empresa a fim de projetar um mobiliário mais adequado. Trata-se de uma fábrica de anéis, alianças, brincos, pulseiras, colares e pingentes* em ouro. A empresa funciona oito horas/dia. O volume de peças a serem fabricadas é variável dependendo da demanda externa. Inicialmente, estudou-se o fluxograma geral da produção. Foram

\footnotetext{
* A partir daqui o termo peças será utilizado para se referir a cada uma dessas jóias.
} 
feitas entrevistas abertas com os funcionários e os gerentes. Com exceção do design, todas as fases do processo são realizadas na própria empresa, da fundição até a venda do produto final. Pode-se afirmar que é um processo semi-artesanal. Apesar do maquinário moderno, o processo depende das habilidades em todas as suas fases. A etapa seguinte do estudo consistiu em observações diretas das atividades em cada posto de trabalho*, onde tentou-se entender os critérios de qualidade perseguidos pelo trabalhador, bem como, as dificuldades enfrentadas. Respeitando a dinâmica da produção, o pesquisador entrevistava o trabalhador durante a execução de suas tarefas, em tempo real, na tentativa de compreender os seus gestos e os seus movimentos com as peças (em cera ou ouro), os instrumentos e o maquinário. As verbalizações simultâneas às observações foram registradas (lápis e papel). Algumas situações foram filmadas, outras fotografadas, com o intuito de uma análise mais detalhada das posturas adotadas em momentos diferentes da jornada de trabalho e em dias diferentes da semana considerando a variabilidade da natureza e do volume das tarefas. Através da análise das filmagens foi realizado um estudo detalhado das posturas, gestos e movimentos adotados pelos trabalhadores, relacionando-os com as operações anteriormente avaliadas.
Os resultados das primeiras observações diretas e abertas permitiram elaborar a hipótese do caráter repetitivo do trabalho em todos os postos analisados. Procedeu-se a quantificação do número de peças produzidas em cada posto da montagem durante 60 minutos, e a seguir calculou-se o ciclo de trabalho (o tempo para a produção de uma peça). Em suma, as variáveis observadas foram: postura principal, ciclo de trabalho, critérios formais e informais de qualidade.

\section{RESULTADOS}

A fábrica é constituída pelos seguintes setores: montagem, fundição, ourivesaria, acabamento final. $\mathrm{O}$ processo de fabricação inicia-se no Setor de Montagem com a preparação do molde e das peças em cera. Esse conjunto (molde e peças) será reunido para, no Setor de fundição, dar origem às peças em ouro que seguirão para o Setor de Ourivesaria e finalmente para o Setor de Acabamento final. Como mencionado, para efeitos desse artigo, será focalizado o Setor de montagem, cujo trabalho é do tipo artesanal contando com apenas uma máquina, a injetora de cera. Trata-se de um processo artesanal semi-mecânico descontínuo. O processo começa no recebimento do modelo, confeccionado em prata, pelo modelista externo.

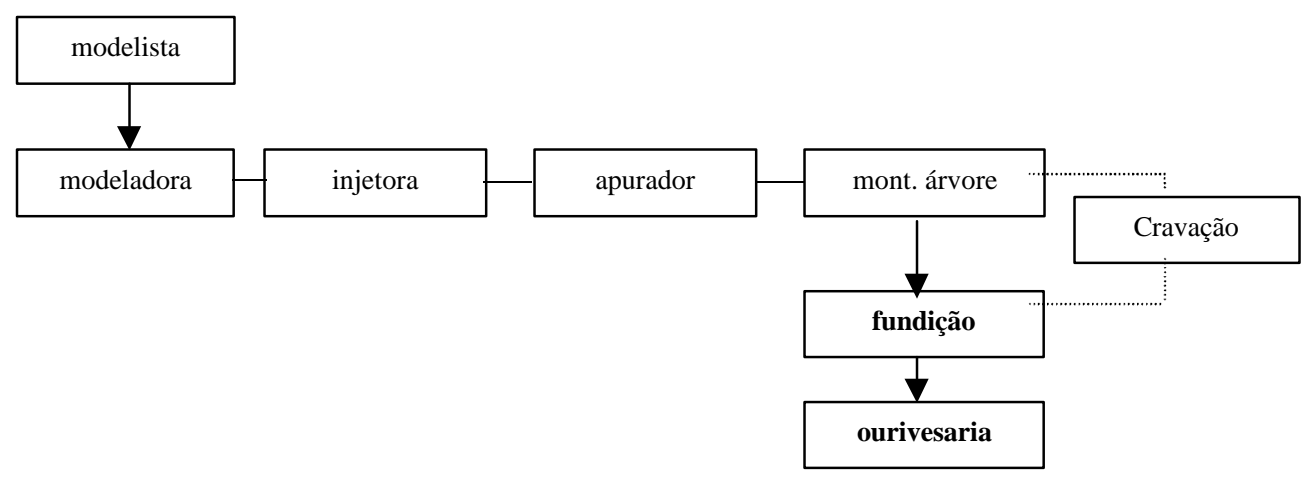

Figura 1 - Fluxograma da produção de peças

$\mathrm{Na}$ montagem existem os seguintes postos: modelagem, injeção de cera, apuração e montagem da árvore (Figura 1). Dependendo do modelo, a peça que está sendo montada será trabalhada no posto de cravação de pedra. Esses postos são dependentes entre si e o ritmo de trabalho é determinado pela quantidade de pedidos. Assim, à medida que o fluxo se inicia, as peças trabalhadas determinam o ritmo do trabalho no

\footnotetext{
* Neste artigo optou-se por apresentar os resultados do estudo ergonômico no setor de montagem.
} 
posto seguinte. Nos seus dizeres "ali atrás vem um monte, não gosto nem de olhar para trás depois do almoço".

\section{Posto da modelagem}

Neste posto a funcionária recebe o modelo em prata preparado pelo estilista para, em seguida, preparar o molde de acordo com a previsão do design. A funcionária verifica o modelo, antes de inseri-lo na fôrma de borracha. O objetivo é criar um negativo em borracha, que em seguida será preenchido com cera, dando origem a peça desse material (protótipo em cera).

A trabalhadora pega a fôrma e com a ajuda de uma espécie de espátula ajeita a borracha flexível, coloca o pino que garantirá a fixação do modelo na injetora de cera. Depois destes procedimentos, coloca o modelo em prata. Em seguida coloca o conjunto na máquina para vulcanização, que permitirá a borracha natural se tornar resistente através de um aquecimento a 170 graus durante 40 minutos.

Terminado o processo de vulcanização, a funcionária usando um estilete corta a borracha para facilitar a retirada do modelo em prata, dando origem ao negativo da peça. Essa operação exige muita cautela ... "o corte não pode deixar marca porque aí a cera escorre". Deixar a marca do corte compromete o trabalho realizado no posto seguinte - injeção de cera - pois, provoca o extravasamento da cera para além da área pretendida pelo modelo, prejudicando, assim, os critérios de qualidade estabelecidos. Para realizar essa operação, a trabalhadora realiza vários movimentos com o punho, principalmente o de rotação. Nota-se a importância dos gestos firmes e precisos e da atenção acurada necessária para atender os critérios de qualidade.

\section{Posto da injeção de cera}

O molde em borracha preparado anteriormente será colocado na máquina-prensa sob uma pressão que controla a quantidade de cera a ser injetada. Há um visor na máquina que indica a pressão, existem oito graus de pressão marcados e disponíveis para serem comandados, porém a trabalhadora não se orienta por essa informação. Ela comanda o nível de pressão necessária por tentativa e erro, orientando-se pelo estado da peça em cera ... "se tiver muita rebarba tem de diminuir a pressão”.

Resumidamente, a tarefa consiste em quatro operações: (1) colocar o molde na injetora; (2) controlar a pressão da injeção; (3) retirar o molde da injetora; (4) retirar o modelo em cera do molde.
Quando a trabalhadora retira o molde da injetora, vai abri-lo para, então, retirar a peça em cera, verificando se há irregularidades. Ela observa a quantidade de rebarba, se o entorno está perfeito, se o pininho, onde uma pedra será cravada, está em condições para tal. Se, por exemplo, um anel em cera tiver muita rebarba, iniciam-se novamente as operações, comandando uma pressão menor. Mas, a cada nova injeção, tudo pode mudar. Ou seja, a pressão ideal para o momento anterior pode não ser para o outro, mesmo que o modelo seja o mesmo. Nota-se nesse processo uma característica da tarefa nem sempre visível a uma análise que negligencie a ação da trabalhadora: ela não só coloca e retira material da máquina, mas procura comandar os níveis de pressão mais ajustados aos objetivos de qualidade.

A funcionária K., três anos de empresa, há um ano trabalha no posto da injetora, cujo ciclo varia em torno de dez segundos e exige manutenção da postura estática, com mínima variação. Trata-se, portanto, de um trabalho repetitivo.

Durante uma hora de observação, ela colocou e retirou da injetora 174 moldes em cera, o ciclo durou 21 segundos. Nessa ação a principal postura adotada foi: sentada, flexão cervical estática, às vezes rotação cervical, flexão anterior estática de tronco, flexão e abdução estática de quadris, flexão estática de joelhos.

As ações de colocar e retirar o molde da máquina, solicitam ambos os membros superiores com adução estática de ombro, flexão estática de cotovelo, antebraço em neutro passando para prono, extensão dinâmica de punho, com alteração do grau, flexão estática das metacarpos, falanges médias e distais. Oposição de polegar e extensão de sua falange distal para apreender a ferramenta utilizada.

A segunda funcionária observada sistematicamente durante uma hora, colocou e retirou da injetora 182 moldes, o ciclo durou 20 segundos. Nessa ação a principal postura adotada foi: sentada, flexão cervical estática, às vezes rotação cervical, flexão anterior estática de tronco, flexão e abdução estática de quadris, flexão estática de joelhos.

As operações de colocar e retirar o molde da máquina, solicitam ambos os membros superiores, havendo no entanto, maior constância do membro superior direito para colocar e do esquerdo para retirar. As ações requerem adução estática de ombro, flexão estática de cotovelo, antebraço em neutro passando para prono, extensão dinâmica de punho, flexão estática das metacarpos, falanges médias e distais. Oposição de polegar e extensão de sua falange distal. 


\section{Posto de cravação de pedras}

Após confeccionadas em cera, as peças serão cravadas com pedras preciosas que, embora parecidas, guardam a sua peculiaridade: forma e tamanho diferentes. Exige-se atenção e cuidado para escolher a pedra do tamanho certo para cada modelo em cera dentro do leque estreito de possibilidades, visto que as pedras já vêm triadas. Essa verificação é importante para a qualidade do produto, evitando que a pedra solte no momento de fundição ..." Crava e na hora da fundição cai ... tem que ter atenção ... olhar o tamanho da pedra para ver direitinho". Segundo a trabalhadora existe o risco do encaixe imperfeito porque a pedra é pequena. Ou seja, a pedra não pode ficar mal colocada, por isso são necessários gestos firmes e precisos dos dedos.

Quanto maior o número de pedras por modelo e quanto menor o tamanho das pedras maior é o tempo despendido para a cravação. Durante a observação da funcionária $\mathrm{W}$., três anos na empresa, há dois meses na cravação, notou-se que o número de pedras por modelo era pequeno (máximo três) e que as pedras eram maiores. Ela cravou 142 pedras em trinta e cinco minutos de observação. O ciclo de trabalho durou em torno de 14 segundos. Nessa ação a principal postura adotada foi: sentada, flexão estática cervical, flexão anterior estática de tronco, flexão e abdução estática de quadril, flexão estática de joelhos.

A ação de cravar as pedras solicita ambos os membros superiores com abdução estática de ombros, flexão estática de cotovelos, pronação estática de antebraço, extensão estática de punho, extensão estática de metacarpos, flexão das falanges médias e distais. Oposição de polegar e flexão de sua falange distal.

\section{Posto da apuração}

Neste posto as peças em cera cravadas com as pedras serão apuradas, quer dizer, ajustadas ao tamanho pretendido (circunferência do anel, por exemplo). Cada molde terá sua circunferência trabalhada, o que exige uma avaliação precisa das suas condições para garantir boa modelagem. O ciclo não é curto, entretanto, as ações realizadas solicitam um esforço muscular estático contínuo importante, como mostra a Figura 2.

Às vezes é necessário cortar o molde para estreitá-lo. O corte é feito com o pirógrafo e as pontas cortadas são coladas com parafina quente. A seguir, com ajuda de um estilete o trabalhador retira o excesso. Verifica se ficou torto, gira o molde, passa o estilete, assopra. Com uma espécie de esponja faz o acabamento procurando deixar a peça o mais limpa possível.

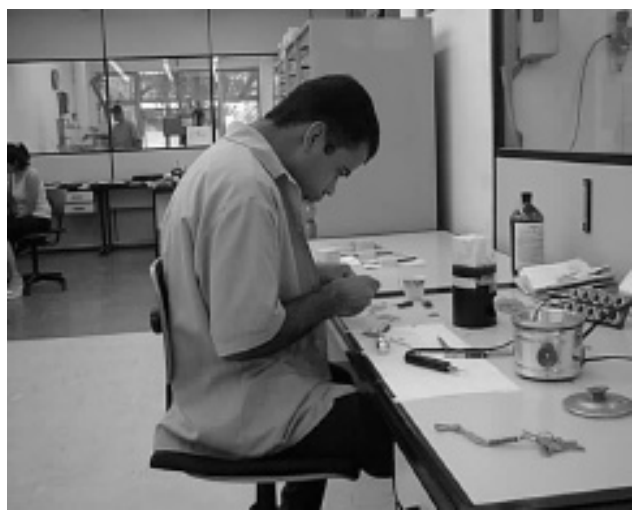

Figura 2 - A postura cervical estática no posto de trabalho de uma fábrica de jóias

Funcionária J., seis meses de empresa trabalhando na apuração. Em uma hora de observação apurou 18 peças, resultando em uma peça a cada três minutos. Nessa ação a principal postura adotada foi: sentada, flexão cervical estática, flexão anterior estática de tronco, flexão e abdução de quadris, flexão de joelhos.

A ação realizada solicita movimentos diferenciados dos membros superiores: membro superior direito em abdução estática de ombro, flexão estática de cotovelo, pronação estática de antebraço, extensão dinâmica de punho, flexão das metacarpos, flexão das falanges médias e distais, oposição do polegar com flexão de sua falange distal; membro superior esquerdo em abdução estática de ombro, flexão estática de cotovelo, supinação estática de antebraço, extensão dinâmica de punho, flexão das metacarpos, flexão das falanges médias e distais, oposição do polegar.

Em uma hora de observação de outra funcionária, dois meses de empresa, apurou 16 peças, resultando em uma peça a cada quatro minutos. Nessa ação a principal postura adotada foi: sentada, flexão cervical estática, flexão anterior estática de tronco, flexão e abdução de quadris, flexão de joelhos.

A ação realizada solicita movimentos diferenciados dos membros superiores: membro superior direito em abdução estática de ombro, flexão estática de cotovelo, pronação estática de antebraço, extensão dinâmica de punho, flexão estática das metacarpos, flexão das falanges médias e distais dos dedos, exceto falange distal do indicador que está em extensão, oposição do polegar; membro superior esquerdo em abdução estática de ombro, flexão estática de cotovelo, supinação estática de antebraço, extensão de punho, flexão das metacarpos, flexão das falanges médias e distais dos dedos, oposição do polegar. 


\section{Posto de montagem da árvore}

Depois que as peças em cera são cravadas com as pedras e apuradas, elas serão fundidas em torno de uma haste também em cera. À medida, que os moldes em cera são fixos nessa haste, forma-se um conjunto com aparência de uma árvore (onde estão pendurados os moldes em cera) que seguirá para uma fôrma em gesso, e, então, levada ao forno. Cera e gesso tem comportamentos diferentes diante do aquecimento. A cera aquecida derrete, deixando um espaço negativo no gesso endurecido com o aquecimento. Este negativo será injetado, dessa vez com ouro no Setor de Fundição.

Com o pirográfo a trabalhadora aquece os moldes em cera (os moldes vêm com um cabo destinado a este fim) de modo a fundi-los com a haste. Há um apoio, regulável, para a árvore que vai se formando. Ela procura mantê-lo no seu ângulo de visão, a $30 \mathrm{~cm}$ do plano de trabalho. A funcionária cuida para deixar os moldes fixos, mas bem delimitados da haste"não pode misturar". Isso significa controlar o ponto de fusão, ter controle sobre a temperatura do pirógrafo: "dependendo da peça, eu abaixo a temperatura, estava muito quente".

Parece ser necessário equilibrar as fusões, de maneira a garantir que a árvore "fique em pê". Ela diz: "quando é pecinha assim, dá mais trabalho... cabe mais, dá mais trabalho".

Durante uma hora de observação fundiu 166 peças, ciclo de 21 segundos. As operações realizadas nesse posto são repetitivas, mas no interior do ciclo repetitivo as variações do modelo da peça pretendida exigem atenção e concentração. Segundo a funcionária quando as peças são grandes (possuem dois cabos), a montagem da árvore é mais rápida porque o número de peças acaba sendo menor devido ao espaço ocupado. Os critérios de qualidade exigem precisão no gesto, pois na montagem da árvore, as peças devem ficar próximas (para que haja espaços vazios na árvore) mas sem se tocarem. Às vezes tem que se colocar uma peça grande em um espaço pequeno e o risco de derreter uma peça vizinha aumenta. Às vezes enquanto amolece as pontas dos cabos das peças a perfuração feita anteriormente na haste para receber o cabo se solidifica, obrigando a trabalhadora a recomeçar. Nota-se assim, a pressão temporal determinada pela natureza do material.

Nessas ações a principal postura adotada foi: sentada, flexão anterior e lateral estática da cervical, flexão anterior estática de tronco, flexão e abdução de quadris, flexão estática de joelhos.

As ações solicitam ambos os membros superiores em abdução estática de ombros, flexão estática de cotovelos, pronação estática de antebraços, extensão estática de punhos, flexão estática das metacarpos, flexão das falanges médias e distais. Oposição do polegar.

\section{DISCUSSÃO}

Como demonstrado, o trabalho no Setor de montagem é repetitivo. O trabalho repetitivo implica um elemento motor, e é definido em termos de força e de tempo. Trata-se da execução de ciclos similares de trabalho que ocorrem mais de uma vez durante a realização de uma tarefa, cuja duração do ciclo é inferior a 30 segundos. Mas, o ciclo apesar de curto é heterogêneo, ou seja, possui componentes variáveis dependendo da presença de fatores externos: tipo de jóia, tipo de pedra, estado da máquina, volume da produção.

Além de repetitivas, as tarefas realizadas solicitam habilidade e destreza manual, movimentos firmes e precisos. Para além da repetição, a precisão dos movimentos realizados na região distal dos membros superiores impõe uma carga estática à musculatura da região proximal e solicita, assim, o conjunto do aparelho músculo-esquelético dos membros superiores. Nota-se a exigência de responsabilidade e atenção no desenrolar das atividades de trabalho o que conduz a um aumento da contração muscular estática, que pode contribuir para a sobrecarga muscular global. Ou seja, os resultados obtidos mostram que esse trabalho apesar de repetitivo não é essencialmente manual. Ele exige concentração, atenção e responsabilidade. Todas essas exigências estão certamente determinando as posturas, principalmente as estáticas cervicais como evidenciado na foto apresentada anteriormente.

As tarefas são realizadas sob pressão temporal e em um contexto onde o erro não é permitido pelas conseqüências possíveis (desperdício de matéria-prima cara). A pressão temporal e o medo de errar podem aumentar a atividade muscular.

Os cinco argumentos: movimentos precisos solicitam o conjunto do aparelho músculo-esquelético dos membros superiores, a responsabilidade, a atenção, o medo de errar, e a pressão temporal aumentam a atividade muscular; fragilizam o pressuposto clássico de que a organização dos segmentos corporais depende somente da vontade dos indivíduos, na maioria das vezes "mal educados". Ou seja, as posturas estáticas no caso analisado são uma composição da tarefa de fabricação de jóias que exige movimentos precisos e controlados das extremidades dos membros superiores. 
O tamanho da peça também é um determinante da maneira como os indivíduos vão adotar posturas. Seria inútil tentar educar os trabalhadores da fábrica de jóias a evitar, por exemplo, a flexão cervical permanente, pois para enxergar detalhes da peça (em sua maioria, muito pequenas) ao mesmo tempo em que ela é trabalhada, o funcionário aproxima sua cabeça para garantir melhor foco (visível) solicitando a flexão cervical. As medidas para o conforto nos postos de trabalho analisados devem ser elaboradas levando-se em conta as ações dos trabalhadores, seus objetivos e impositivos do objeto trabalhado (pequeno, caro e bonito). Tentar prescrever a postura ideal é inútil, seria melhor agir sobre o processo técnico-organizacional (LIMA, 2000c).

\section{CONCLUSÃO}

O profissional da Terapia ocupacional pode se beneficiar dos resultados da AET quando chamado a orientar posturas no trabalho, à medida que ele integra seu raciocínio clínico às razões que levam aquele trabalhador, a permanecer em uma postura estática por tempo prolongado. É através da mediação pelo trabalho que a AET pretende abordar e esclarecer os problemas posturais.

ALVES, G.B.O., ASSUNÇÃO, A.A., LUZ, M.G. The ergonomics approach in the study of the postures of the work: the case a jewel industry. Rev. Ter. Ocup. Univ. São Paulo, v. 13, n. 3, p. 111-7, set./dez. 2002.

\begin{abstract}
The objective of this paper is to discuss the practice of Occupational Therapy on the assessment of postures adopted by workers in real situations. An ergonomic study was carried out in a jewel industry by means of open interviews between managers and workers, analyses of adopted postures, description of work cycle duration, and evaluation of informal and formal quality criteria applied to the final products. The results pointed out for the repetitive nature of the work in the positions studied. On the other hand, the components were heterogeneous, demanding attention and concentration. These cognitive functions, among other determinants, influenced the adopted postures. The myth of an ideal posture and the limitations of the practice of Occupational Therapy approach that do not take into account the significance of adopted postures in its evaluations are discussed.
\end{abstract}

KEYWORDS: Evaluation studies. Occupational therapy/trends. Posture. Human engineering. Interviews. Industry/classification. Workers.

\title{
REFERÊNCIAS
}

ABRAHAO, J. I. Reestruturação produtiva e variabilidade do trabalho: uma abordagem da ergonomia. Psicologia: Teor. Pesq., v. 16, n. 1, p. 49-54, 2000.

AMERICAN JOURNAL OF OCCUPATIONAL THERAPY, v. 53, n. special issue, 322 p., 1999.

ASSUNÇÃO, A. A. Os aspectos biomecânicos explicam os problemas músculo-esqueléticos em trabalhadores expostos a tarefas repetitivas? In: CONGRESSO DA ASSOCIAÇÃO NACIONAL DE MEDICINA DO TRABALHO, 11., Belo Horizonte, 29 abr. 3 maio 2001. [CDROM].

ASSUNÇÃO, A. A.; LIMA, F. P. A. A nocividade no trabalho: contribuição da ergonomia. In: MENDES, R. (Org.) Patologia do trabalho. Rio de Janeiro: Atheneu, 2002.

LIMA, F. P. A. A ergonomia como instrumento de segurança e melhoria das condições de trabalho. In: SEMINÁRIO DE SEGURANÇA DO TRABALHO E ERGONOMIA FLORESTAL - ERGOFLOR, 1., Belo Horizonte, jun. 2000. Anais. Belo Horizonte, 2000a.

LIMA, F. P. A. A formação em ergonomia: reflexões sobre algumas experiências de ensino da metodologia de análise ergonômica do trabalho. In: KIEFER, C.; FAGÁ, I., SAMPAIO, M. R. Trabalho, educação e saúde. Vitória: Fundacentro, 2000b.

LIMA, F. P. A. Ergonomia e organização do trabalho: a perspectiva da atividade. Produção, n. esp., 2000c.

TROMBLY, C. A. Antecipating the future: assessement of occupational function. Am. J. Occup. Ther., v. 47, p. 253-7, 1993.

Recebido para publicação: 11/03/2002

Aceito para publicação: 17/06/2002 